\section{Expression of progesterone receptor membrane component-1 in bovine reproductive system during estrous cycle}

\author{
A.M. Luciano, ${ }^{1}$ D. Corbani, ${ }^{1}$ V. Lodde, ${ }^{1}$ \\ I. Tessaro, ${ }^{1}$ F. Franciosi, ${ }^{1}$ J.J. Peluso, ${ }^{2}$ \\ S. Modina ${ }^{1}$
}

'Department of Animal Sciences, Faculty of Veterinary Medicine, University of Milan, Italy; 'Department of Cell Biology, University of CT Health Center, Farmington, CT, USA

\begin{abstract}
Several reports suggest the participation of progesterone receptor membrane component 1 (PGRMC1) in progesterone signaling in the reproductive system. This study aimed at investigating the presence and localization of PGRMC1 in bovine ovary, oviduct and uterus, during the follicular and luteal phases of the estrous cycle. In the ovary, PGRMC1 has been detected in surface germinal epithelium, granulosa cells, theca cells and in the germinal vesicle of the oocytes at all stages of folliculogenesis. In the corpus luteum the expression of PGRMC1 was influenced by the stage of the estrous cycle. In the oviducts and in the uterus horns, PGRMC1 was immunolocalized in the luminal epithelium, in the muscle layer cells and in the endothelial cells. In the uterus, PGRMCl was intensely localized also in the glandular endometrium. However, in the oviducts and in the uterus horns, the localization of PGRMC1 was independent on the stage of the estrous cycle and on whether evaluating the ipsilateral or the contralateral organ. In conclusion, the present immunohistochemical study showed that PGRMC1 is located in various compartments of the bovine female reproductive organs. With the exception of the corpora lutea, PGRMC1 localization showed similar pattern during different stages of the estrous cycle.
\end{abstract}

\section{Introduction}

Progesterone receptor membrane component 1 (PGRMC1) belongs to the membraneassociated progesterone receptor (MAPR) proteins family that is widespread in eukaryotes and involved in regulating numerous biological functions. ${ }^{1}$ PGRMC1 is predominantly located in intracellular membranes and colocalizes with the endoplasmic reticulum and Golgi apparatus in rat liver cells and hippocampal Purkinje cells. ${ }^{2,3}$ Several studies described a nuclear or chromosomal localization. PGRMC1 was detected in nuclear extracts of HeLa cells, ${ }^{4}$ among the protein of the human mitotic spindles, ${ }^{5,6}$ and recently has been proposed in regulating microtubule stability in human and rat ovarian cell mitosis. ${ }^{7,8}$ Various ovarian cell types, including granulosa cells and ovarian surface epithelial cells as well as ovarian tumors, express PGRMC1 where it plays an essential role in promoting the survival of both normal and cancerous ovarian cells in vitro. ${ }^{9}$

Recently, PGRMC1 expression has been demonstrated in several female reproductive tissues in different mammalian species. PGRMC1 has been detected in uterine and placental tissues of the mouse and human ${ }^{10}$ and it is among the proteins that were differentially expressed in the human endometrium during menstrual cycle. ${ }^{11}$

Other reports investigated the localization and function of PGRMC1 in the ovary. In particular immunohistochemical studies localized PGRMC1 in granulosa cells, theca cells and ovarian surface epithelial cells (germinal epithelium) in rat. ${ }^{12}$ Moreover the expression of PGRMC1 mRNA was found in granulosa or luteal cells in humans, ${ }^{13}$ mice, ${ }^{14}$ pigs $^{15}$ and cows. ${ }^{16}$ Several works suggest that progesterone mediates its antiapoptotic action through PGRMC1. 17,18 PGRMCl is also expressed in bovine, ${ }^{19}$ rat $^{12}$ and human oocytes. ${ }^{20}$ Recently, PGRMC1 was associated to the meiotic spindle suggesting a role in oocyte maturation, which may be specifically related to the mechanism by which chromosomes segregate ${ }^{19}$ However, with regard to localization of the protein, a recent work did not detect PGRMC1 in the bovine oocyte. ${ }^{21}$ To date there is little information on the localization of PGRMC1 in the reproductive organs of the cow. Thus, the aim of the present study was to examine the presence and localization of PGRMC1 in a variety of cow reproductive organs, including ovary, oviduct and uterus during the follicular and luteal phases of the estrous cycle using immunohistochemistry.

\section{Materials and Methods}

\section{Tissue collection}

All the chemicals used in this study were purchased from Sigma Chemical Company except for those specifically mentioned. Bovine ovary, oviduct and uterus were recovered at a local abattoir (INALCA JBS S.p.A.,
Correspondence: Alberto M. Luciano, Sezione di Anatomia ed Istologia Veterinaria, Dipartimento di Scienze Animali, Facoltà di Medicina Veterinaria, Università degli Studi di Milano, via Celoria 10, 20133 Milano, Italy.

Tel. +39.02.50317969 - Fax: +39.02.50317980

E-mail: alberto.luciano@unimi.it

Key words: Uterus, oviduct, ovary, corpus luteum, follicle, oocyte, progesterone receptor

Acknowledgements: the authors wish to thank Dr. Nadia Fiandanese for her excellent technical support

Contributions: DC, VL, IT, FF laboratory experiments performing; AML, VL, SM results analysis and interpretation; AML, VL, JJP, SM, research theme defining, methods designing and manuscript writing. All authors approved the manuscript final version.

Received for publication: 28 July 2011.

Accepted for publication: 24 August 2011.

This work is licensed under a Creative Commons Attribution NonCommercial 3.0 License (CC BYNC 3.0).

CC Copyright A.M. Luciano et al., 2011

Licensee PAGEPress, Italy

European Journal of Histochemistry 2011; 55:e27 doi:10.4081/ejh.2011.e27

Ospedaletto Lodigiano, LO, IT 2270M CE, Italy) from non-pregnant dairy cows, 4 to 8 yrs old, subjected to routine veterinary inspection and in accordance to the specific health requirements stated in Council Directive 89/556/ECC and subsequent modifications, and were transported to the laboratory on ice. The stage of the estrous cycle was assessed by morphological observations of the ovary. ${ }^{22}$ In particular, animals in which one of the two ovaries presented an active corpus luteum were classified as belonging to luteal phases of estrous cycle while animals in which one of the two ovaries presented the ovulatory follicle and a regressed corpus luteum were classified as belonging to follicular phases of estrous cycle. ${ }^{23,24}$

For each animal, both ovaries were transversely cut and 2-4 fragments of corpus luteum and 2-4 fragments of ovarian cortex were collected; from both oviducts samples of isthmus, ampulla and infundibulum were separated. Finally the apical third of each uterine horns was isolated dissecting at about $5 \mathrm{~cm}$ from the uterus-isthmic junction. ${ }^{25}$ All samples were fixed in B5 (Formalin-Mercury II Chloride) fixative (Bio-Optica, Milan, Italy) for 12-24 h, dehydrated by a graded series of ethanol, cleared with xylene, paraffin embedded and sectioned at $5 \mu \mathrm{m}$ on glass slides, previously treated with Vectabond (Vector Laboratories, Burlingame, CA, USA) to enhance the adherence of tissue. 


\section{Western blot analysis}

Western blot analysis was performed as previously described with minor modifications. ${ }^{19}$ Briefly, aliquots of $50 \mathrm{mg}$ of ovarian cortex and corpus luteum were homogenized in RIPA buffer, which was supplemented with complete protease and phosphatase inhibitor cocktails, incubated for $30 \mathrm{~min}$ on ice and then centrifuged at $14,000 \mathrm{~g}$ for $20 \mathrm{~min}$ at $4^{\circ} \mathrm{C}$. Total amount of protein was determined using the Bio-Rad Protein Assay (Biorad) and $20 \mu \mathrm{g}$ of total protein was used for western blot analysis. Equal protein loading was verified by Ponceau staining. PGRMC1 immunodetection was conducted using different concentrations ( $1 \mu \mathrm{g} / \mathrm{mL}$ and $0.3 \mu \mathrm{g} / \mathrm{mL}$ ) of a rabbit polyclonal antibody (Sigma Prestige, Cat. No.HPA002877) or a goat polyclonal antibody (AbCam, Cat. No. ab48012) overnight at $4^{\circ} \mathrm{C}$. PGRMC1 was revealed using an anti-rabbit or anti-goat HRPlabelled antibodies (1:8000) and Super Signal ${ }^{\circledR}$ West Pico Chemiluminescence Substrate (PIERCE Biotechnologies Inc., Rockford, IL, USA). Negative controls were conducted by omitting the primary antibodies.

\section{Immunohistochemistry}

Indirect immunohistochemistry was carried out to evaluate the expression and localization of PGRMC1. Endogenous peroxidase activity was eliminated by incubation with $3 \%(\mathrm{v} / \mathrm{v})$ $\mathrm{H}_{2} \mathrm{O}_{2}$ in methanol for $30 \mathrm{~min}$. Then sections were incubated with $10 \%(\mathrm{v} / \mathrm{v})$ normal goat serum or normal rabbit serum, $0.3 \%(\mathrm{v} / \mathrm{v})$ Triton X-100 and 3\% (w/v) bovine serum albumin (BSA) in phosphate buffered saline (PBS) for 30 min to block non-specific binding of secondary antibody. In a preliminary study the sections were incubated overnight at $4{ }^{\circ} \mathrm{C}$ with different concentrations $(0.96,0.48,0.24$ or $0.16 \mu \mathrm{g} / \mathrm{mL}$ ) of polyclonal rabbit anti-PGRMC1 (Sigma Prestige) or polyclonal goat antiPGRMC1 (Abcam) diluted in PBS with 1\% (w/v) BSA and $0.3 \%(\mathrm{v} / \mathrm{v})$ Triton X-100. In all the subsequent experiments the rabbit polyclonal antibody was used at a concentration of $0.48 \mu \mathrm{g} / \mathrm{mL}$. Primary antibodies were detected by using a biotinylated anti-rabbit or anti goat IgG (Vector Laboratories), diluted 1:400 in PBS with $1 \%(\mathrm{w} / \mathrm{v})$ of BSA and detected with the Vectastain Elite $\mathrm{ABC}$ kit (Vectastain Elite ABC kit, Vector Laboratories). For color development, all sections were incubated with $D A B$ substrate (DAB substrate kit for peroxidase, Vector Laboratories) for 2 min. After staining, the samples were counterstained with hematoxylin QS (Vector Laboratories). Negative controls were performed by omitting the primary antibodies. Samples were analyzed on a Nikon Eclipse microscope (Nikon Corp., Tokyo, Japan) in bright field at a magnification of 200X-400X.

\section{Results}

Preliminary studies were conducted in order to compare the specificity and the sensitivity of two antibodies (polyclonal rabbit antiPGRMC1 and polyclonal goat anti-PGRMC1) by western blot and immunohistochemical analysis with different primary antibodies concentrations. Western blot analysis confirmed that
PGRMC1 was specifically detected in ovarian cortex as $\mathrm{a} \approx 26 \mathrm{kDa}$ protein (Figure $1 \mathrm{~A}$ ). However, only the polyclonal rabbit antiPGRMC1 detected the protein, while under the same experimental conditions the goat polyclonal antibody did not. Conversely, the goat polyclonal antibody only detected the $26 \mathrm{kDa}$ protein when higher amounts of total proteins (100 and $50 \mu \mathrm{g}$ ) were loaded on the gel (Figure 1B). Moreover, antibody titration on immuno-

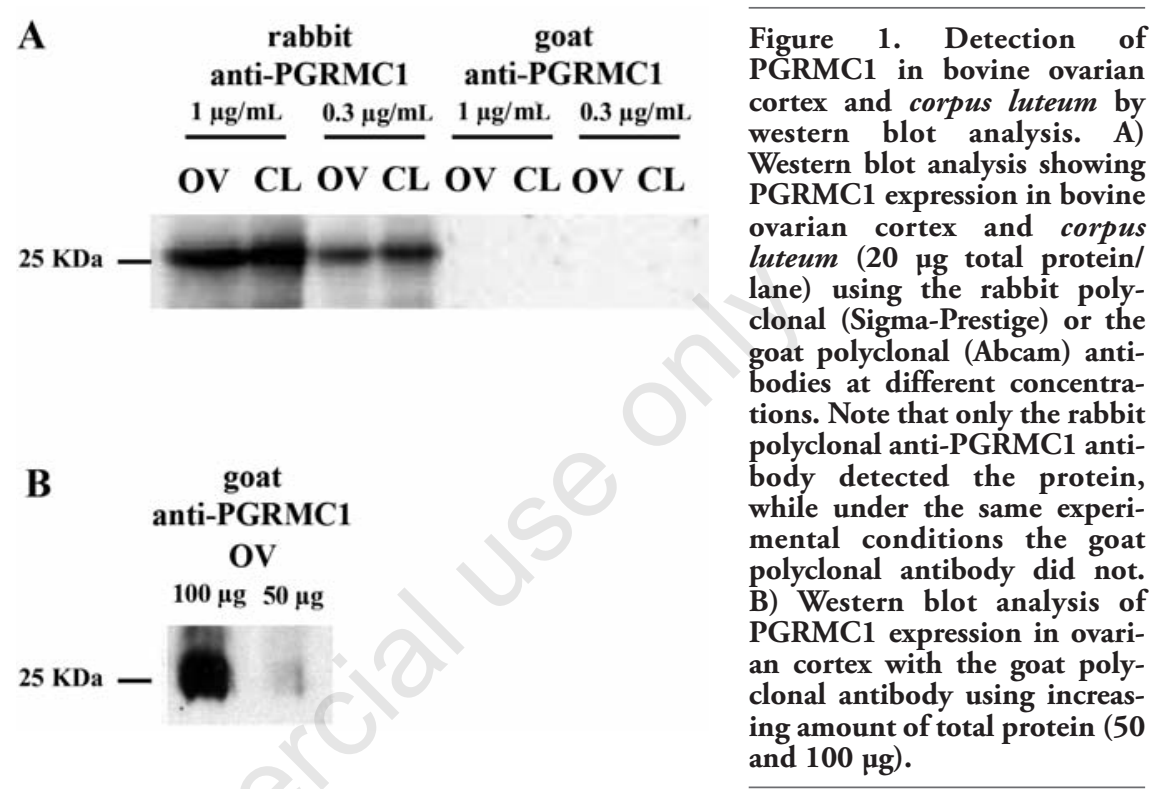

Table 1. Immunohistochemical localization of PGRMC1 in the reproductive tracts during estrous cycle. PGRMC1 is indicated as intense $(+)$ weak $( \pm)$ or negative signal in the different organs.

\begin{tabular}{ccc} 
& \multicolumn{2}{c}{ Estrous cycle } \\
Tissue/cell type & Cytoplasm phase & Luteal phase \\
Nucleus & Cytoplasm Nucleus
\end{tabular}

\section{Ovary follicle}

Oocyte

Granulosa cells

Theca cells

Endothelial cells

\begin{tabular}{ll} 
Stromal tissue & \\
Stromal cells & \pm \\
Endothelial cells & + \\
Germinal epithelium & + \\
\hline
\end{tabular}

\section{Corpus luteum}

Luteal cells

Endothelial cells

\pm
+
+
\pm
+
+

Oviduct

Epithelial cells

Stromal cells

Muscle layer cells

Endothelial cells

$+$

\begin{tabular}{llll} 
\pm & + & \pm & + \\
+ & + & + & + \\
+ & + & + & + \\
+ & + & + & + \\
\pm & & & \\
+ & \pm & \pm & \pm \\
+ & + & + & + \\
\hline
\end{tabular}

Uterus

Luminal epithelial cells

Glandular epithielial cells

Stromal cells

Muscle layer cells

Endothelial cells

\begin{tabular}{llll}
+ & + & + & + \\
+ & + & + & + \\
\pm & \pm & \pm & \pm \\
+ & + & + & + \\
+ & + & + & + \\
\hline
\end{tabular}


A

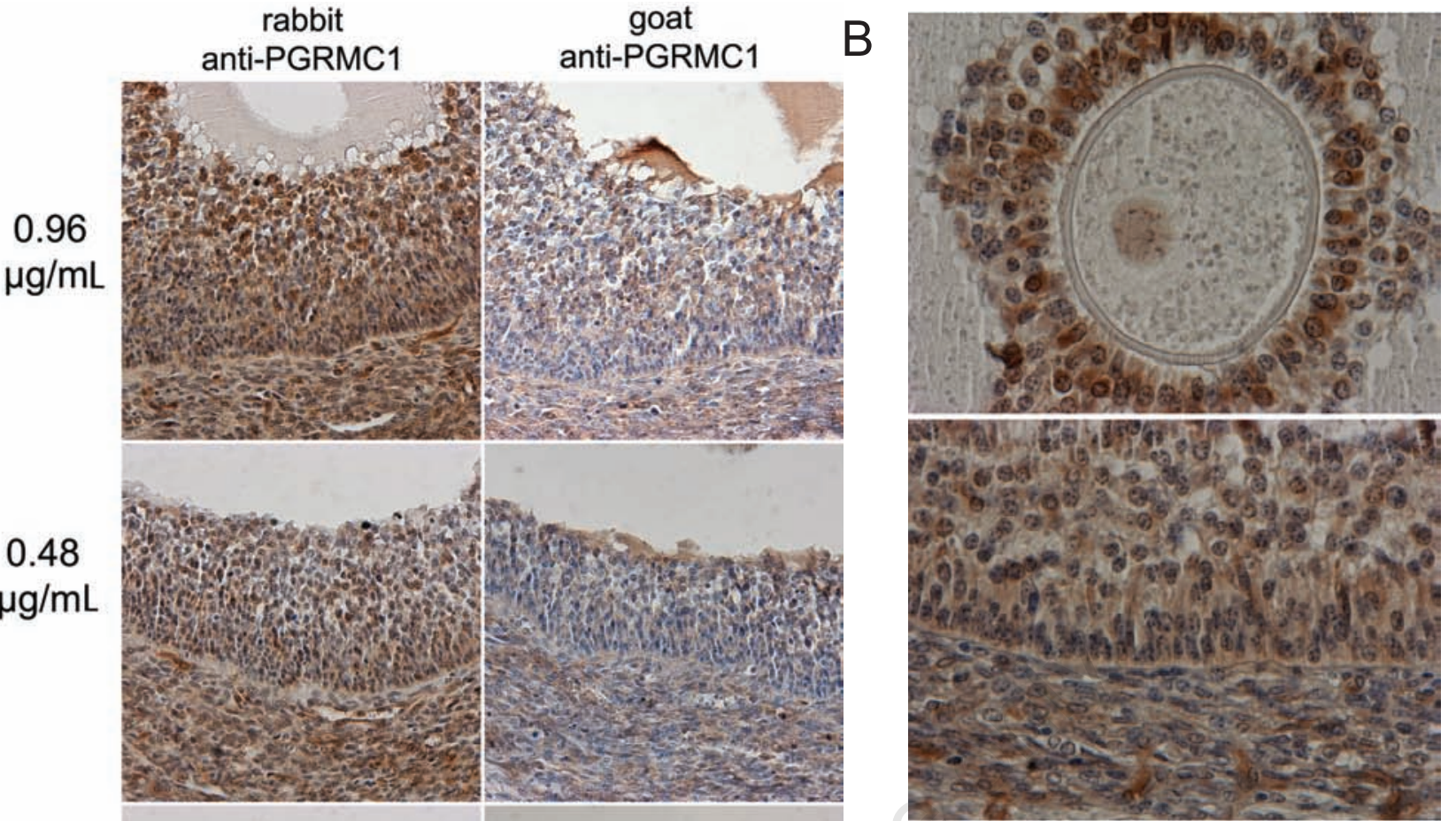

0.24

$\mu \mathrm{g} / \mathrm{mL}$

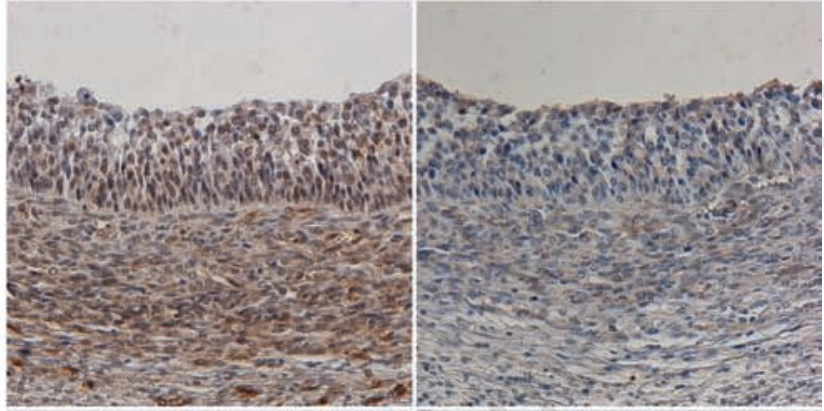

\subsection{6 \\ $\mu \mathrm{g} / \mathrm{mL}$}

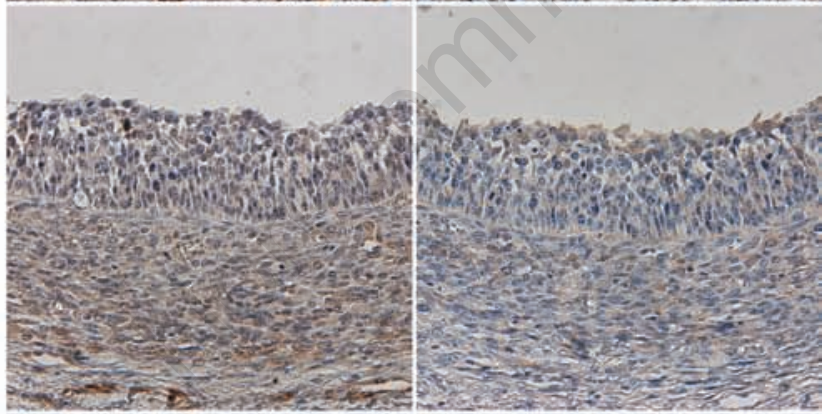

Negative
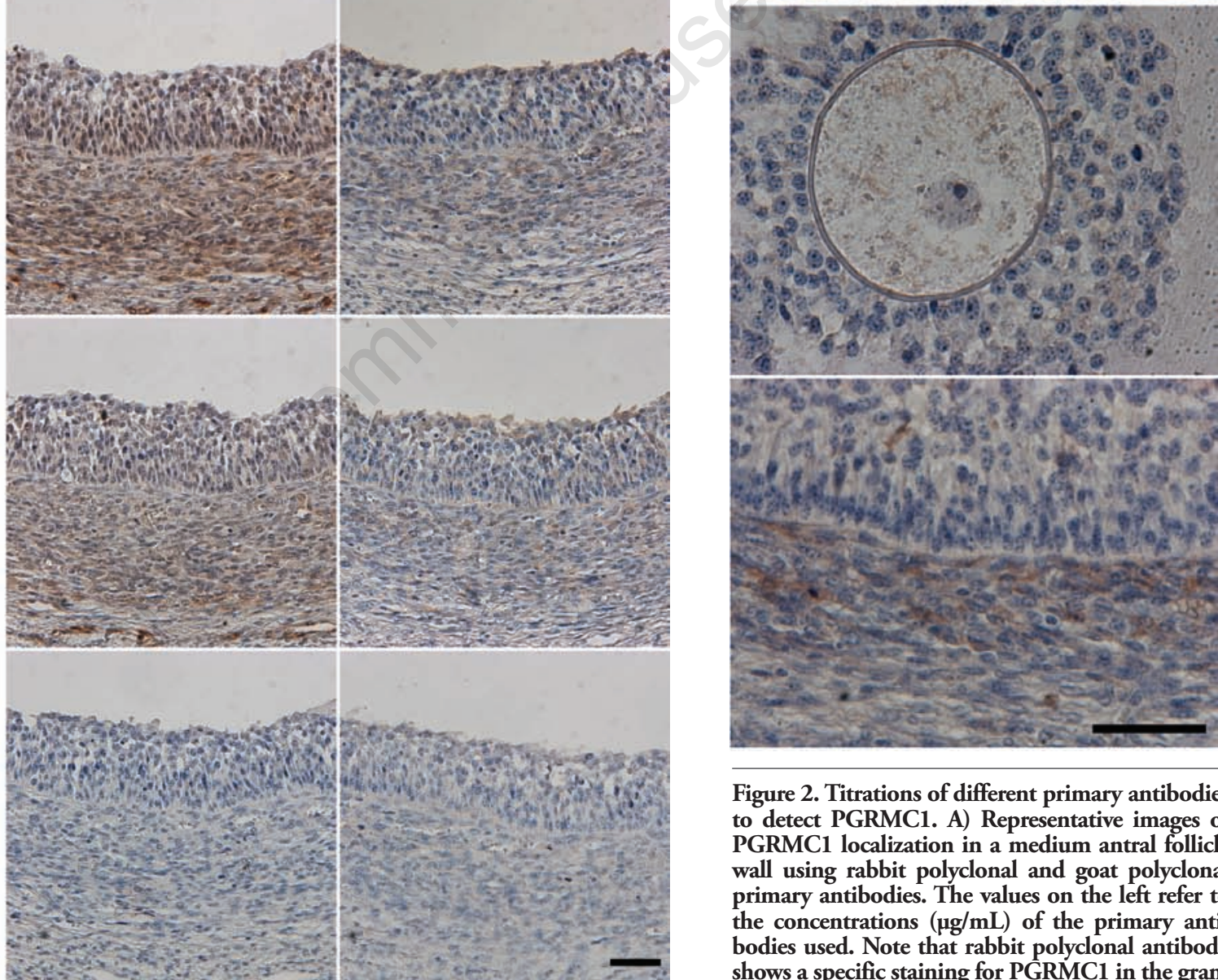

Figure 2. Titrations of different primary antibodies to detect PGRMC1. A) Representative images of PGRMC1 localization in a medium antral follicle wall using rabbit polyclonal and goat polyclonal primary antibodies. The values on the left refer to the concentrations $(\mu \mathrm{g} / \mathrm{mL})$ of the primary antibodies used. Note that rabbit polyclonal antibody shows a specific staining for PGRMC1 in the granulosa cells, in the theca layer and in the endothelial

cells of blood vessels at all concentration used, whereas weaker signal was detected by the goat polyclonal antibody under the same experimental conditions. No immunoreactivity was seen in negative controls where incubation with the primary antibodies was omitted. Final magnification, 200X; scale bar, $50 \mu \mathrm{m}$. B) Representative images showing details of PGRMC1 localization in oocytes and medium antral follicle wall using the two antibodies under the same experimental conditions at a concentration of $0.48 \mu \mathrm{g} / \mathrm{mL}$. Note that rabbit polyclonal primary antibody exhibits a specific staining for PGRMC1 in cumulus cells, germinal vesicle, granulosa cells, theca layer and endothelial cells (upper images) when compared with the goat polyclonal primary antibody (lower images). Final magnification, 400X; scale bar, $50 \mu \mathrm{m}$. 
histochemistry showed a higher sensitivity of the polyclonal rabbit anti-PGRMC1 since this antibody detected PGRMC1 in the granulosa cells, in the theca layer and in the endothelial cells of blood vessels at all concentration tested, whereas the goat polyclonal antibody detected a much weaker signal at the corresponding concentration (Figure 2A,B). In addition the rabbit polyclonal detected a much higher PGRMC1 signal in cumulus cells and germinal vesicle of the oocyte when compared with the goat polyclonal used at the same concentration (Figure 2B). Therefore, the polyclonal rabbit anti-PGRMC1 antibody, at a concentration of $0.48 \mu \mathrm{g} / \mathrm{mL}$ was utilized in further experiments to assess PGRMC1 localization in bovine ovary, oviduct and uterine horn.

A total of 8 animals (4 for each phase of the estrous cycle) were analyzed for PGRMC1 localization. Data are shown in Figures 3, 4 and 5 and summarized in Table 1.

In all experiments, negative controls were conducted in the absence of the primary antibody and did not show any staining.

In the ovary, immunohistochemical studies showed that PGRMC1 was expressed in the follicles during all the stages of folliculogenesis, in the oocyte and in its surrounding cumulus cells, both in the nucleus and inside the cytoplasm (Figure 3). Oocyte showed a positive staining in the germinal vesicle (GV), while the ooplasm displayed only a weak signal (Figure 3A,B). In the cumulus oophorus, granulosa cells lying closer to the oocyte exhibited a more intense signal than granulosa cells in the outer layers (Figure 2B). PGRMC1 was also detected in theca layers (Figure 3C). Furthermore, PGRMC1 was immunolocalized in the germinal epithelium of the ovarian surface (Figure 3D) and in the endothelial cells of the stromal vessels (arrows in Figure 3A,B,C). On the contrary, in ovarian stromal tissue cells PGRMC1 was weakly detected. Immunolocalization of PGRMC1 revealed a similar expression pattern for the follicular and luteal phase of the estrous cycle and differences were not observed between the two ovaries of the same animal.

In contrast, in the corpus luteum PGRMC1 was differently immunolocalized depending on the stage of the estrous cycle (Figure 4). During the luteal phase (Figure 4A) most of the luteal cells showed a cytoplasmic staining for PGRMC1, with signal intensity varying from intense to weak, while the signal was completely absent only in a few cells. During the follicular phase (Figure 4B) PGRMC1 was detected as a weak signal in the cytoplasm of most of the cells. In both phases PGRMC1 was expressed in the endothelial cells and was detected as an intense to weak signal in the nuclei of the luteal cells.

Microscopic examination of PGRMC1 localization in the oviduct revealed a specific nuclear and cytoplasmic staining for PGRMC1 in the luminal epithelium (Figure 5A,B), in the muscle layers (Figure 5C), as well as in the endothelial cells. On the contrary PGRMC1 was weakly expressed in the cells of lamina propria and submucosa (stromal cells). No differences were observed between infundibulum (Figure 5A), ampulla (Figure 5B), and isthmus (Figure 5C), neither in follicular nor luteal phase, either between the two organs of the same animal. In the uterus, PGRMC1 was observed as
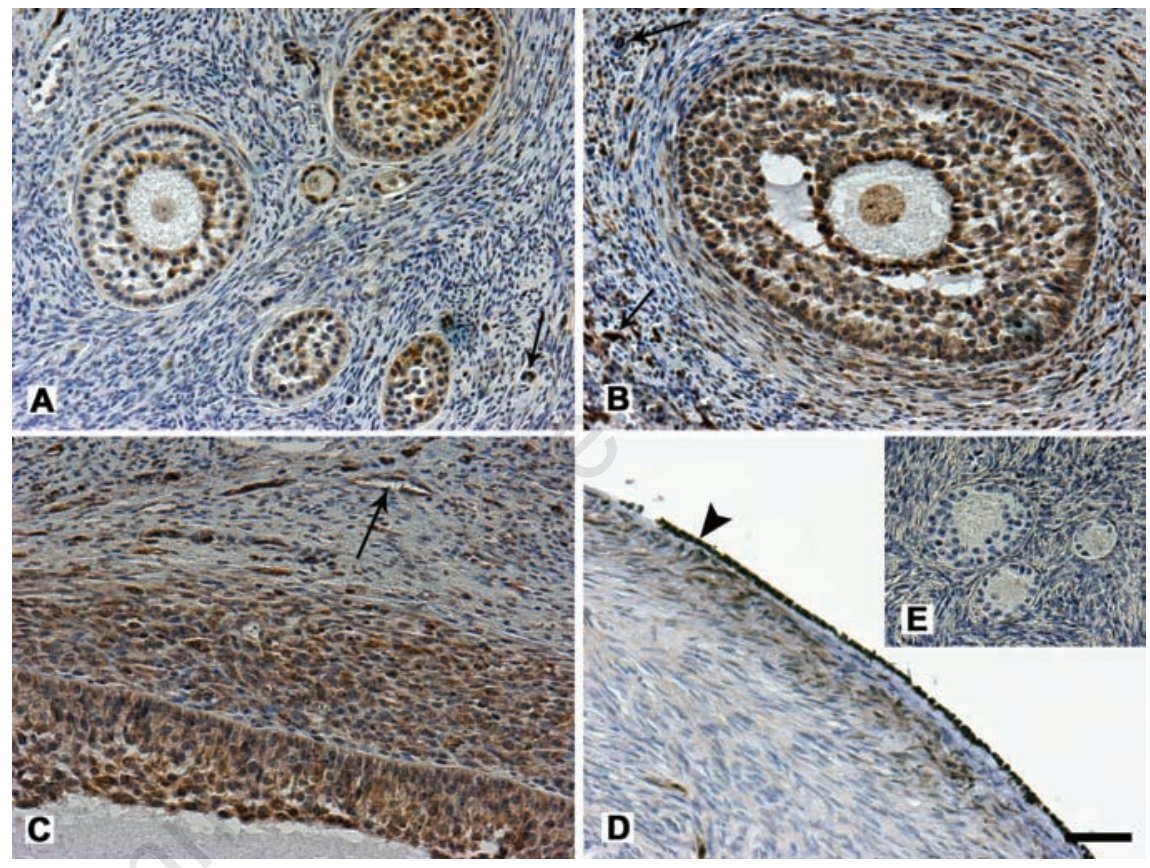

Figure 3. Immunohistochemical localization of PGRMC1 in bovine ovarian cortex. PGRMC1 is localized in primordial, primary and secondary follicles (A), in early antral follicles (B) and in antral follicles (C). Note that the expression of PGRMC1 is more evident in the granulosa cells closer to the oocyte, in the GV and in the internal theca layer. PGRMC1 was detected in the endothelial cells (arrows) and in the germinal epithelium at the ovarian surface (D, arrowhead). No immunoreactivity was seen in negative control where incubation with the primary antibody had been omitted (E). Final magnification, 200X; scale bar, $50 \mu \mathrm{m}$.

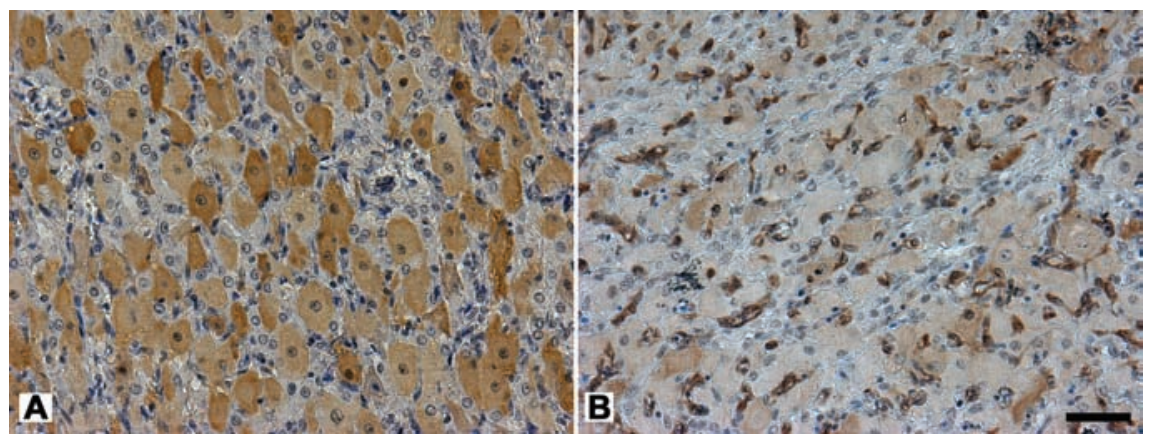

Figure 4. Immunohistochemical localization of PGRMC1 in bovine corpora lutea during the luteal and follicular phase of the estrous cycle. During the luteal phase (A) PGRMC1 is localized in the cytoplasm of the luteal cells displaying an heterogeneous signal, varying from intense to weak to completely absent. During the follicular phase (B) PGRMC1 is detected as a weak signal in the cytoplasm of most of the luteal cells. In both phases PGRMC1 is expressed in the endothelial cells and is weakly detected in the nucleus of the luteal cells. Final magnification, 200X; scale bar, $50 \mu \mathrm{m}$. 


\section{Discussion}

To the best of our knowledge, this is the first study that describes PGRMC1 immunolocalization in various parts of bovine reproductive system. In the ovary, PGRMC1 has been detected in germinal epithelium, granulosa cells, theca cells, and oocyte in all stages of folliculogenesis, in agreement with previous studies conducted in rat. ${ }^{12}$ Data from the literature indicate that, in the ovary, PGRMC1 is continuously and highly expressed during fetal development in rat and cow and it has been suggested that PGRMC1 participates through a progesterone-dependent mechanism to the process of primordial follicle assembly. ${ }^{26,27}$

In this study, PGRMC1 was intensely localized in the GV of oocytes. This confirms our previous immunofluorescence study on the oocyte where PGRMC1 was restricted in the GV after follicle isolation. ${ }^{19}$ In the oocyte, PGRMC1 has a role in oocyte maturation, which may be specifically related to the mechanism of chromosomes segregation. ${ }^{19}$ However, other Authors were unable to detect PGRMC1 in the bovine oocyte,,$^{21}$ while it was detectedin the surrounding granulosa cells. This difference may be due to the different sensitivity of the antibody used and to the shorter incubation time employed in the previous study (3 h). As indicated in our study, the polyclonal rabbit anti-PGRMC1 antibody showed a much higher sensitivity respect to the polyclonal goat anti-PGRMC1 antibody and the titration assay demonstrated that only high concentrations of the polyclonal goat anti-PGRMC1 antibody were able to detect a specific signal by western blot and immunohistochemistry under our experimental conditions.

Our observations in the ovary and corpus luteum support previous studies where the expression of PGRMC1 was found in granulosa and luteal cells in human, ${ }^{13}$ mouse, ${ }^{14}$ rat, ${ }^{12}$ pig ${ }^{15}$ and cow. ${ }^{16,28}$ PGRMC1 positivity in endothelial cells of the corpus luteum reported in previous study on PGRMC1 expression in $\operatorname{cow}^{28}$ was also confirmed by our observations. Furthermore, in the present work, the expression of PGRMC1 in the corpus luteum was found to be influenced by the stage of the estrous cycle. In the luteal phase, PGRMC1 was intensely localized in the cytoplasm while in the follicular phase a weak PGRMC1 signal was detected in the cytoplasm of most of the cells. This stage-specific localization of PGRMC1 could be explained through the functional status of the corpus luteum. Beside its possible involvement in steroid synthesis in the active corpus luteum, the ability of PGRMC1 in promoting luteal cell viability by mediating progesterone anti-apoptotic action was demonstrated. $^{13}$

PGRMCl was detected among the proteins that were differentially expressed in the human endometrium during the menstrual cycle. ${ }^{11}$ This study showed that PGRMCl protein was more highly present in the proliferative (luteal) than the secretory (follicular) phase and immunostaining data revealed that it was confined to the stromal component of proliferative phase endometrium. Analogously, microarray profiling of progesterone-regulated endometrial genes during the rhesus monkey secretory phase showed a down regulation of PGRMC1. ${ }^{29}$ These findings were confirmed also in mice, ${ }^{10}$ where PGRMC1 expression was up-regulated in the stromal compartment of the uterus from estrus to metestrus and reduced during diestrus. In the bovine, our study showed that PGRMC1 localization in the oviducts and in the uterus horns, was similar in the ipsilateral or the contralateral organs and was irrespective of the stage of the estrous cycle. This difference between species may be explained by the different technique adopted since the immunochemical detection of the protein must be confirmed by a quantitative analysis. Moreover, the level of the transcript must be determined in order to assess whether or not the phase-independent localization of PGRMC1 observed in this study, in bovine oviduct and uterus, is accompanied by a phaseindependent PGRMC1 transcript level.

In the present study we did not observe differences in PGRMC1 localization in the uterus between the luteal and follicular phases. However, we do not exclude that these differences could arise during pregnancy. In fact, a decrease in PGRMCl has been observed in human myometrium during term or preterm labor, where PGRMCl down-regulation might contribute to the functional withdrawal of progesterone's action and shift the balance to a state of increased uterine contractility. ${ }^{30}$ Moreover, PGRMC1 was described in the human and
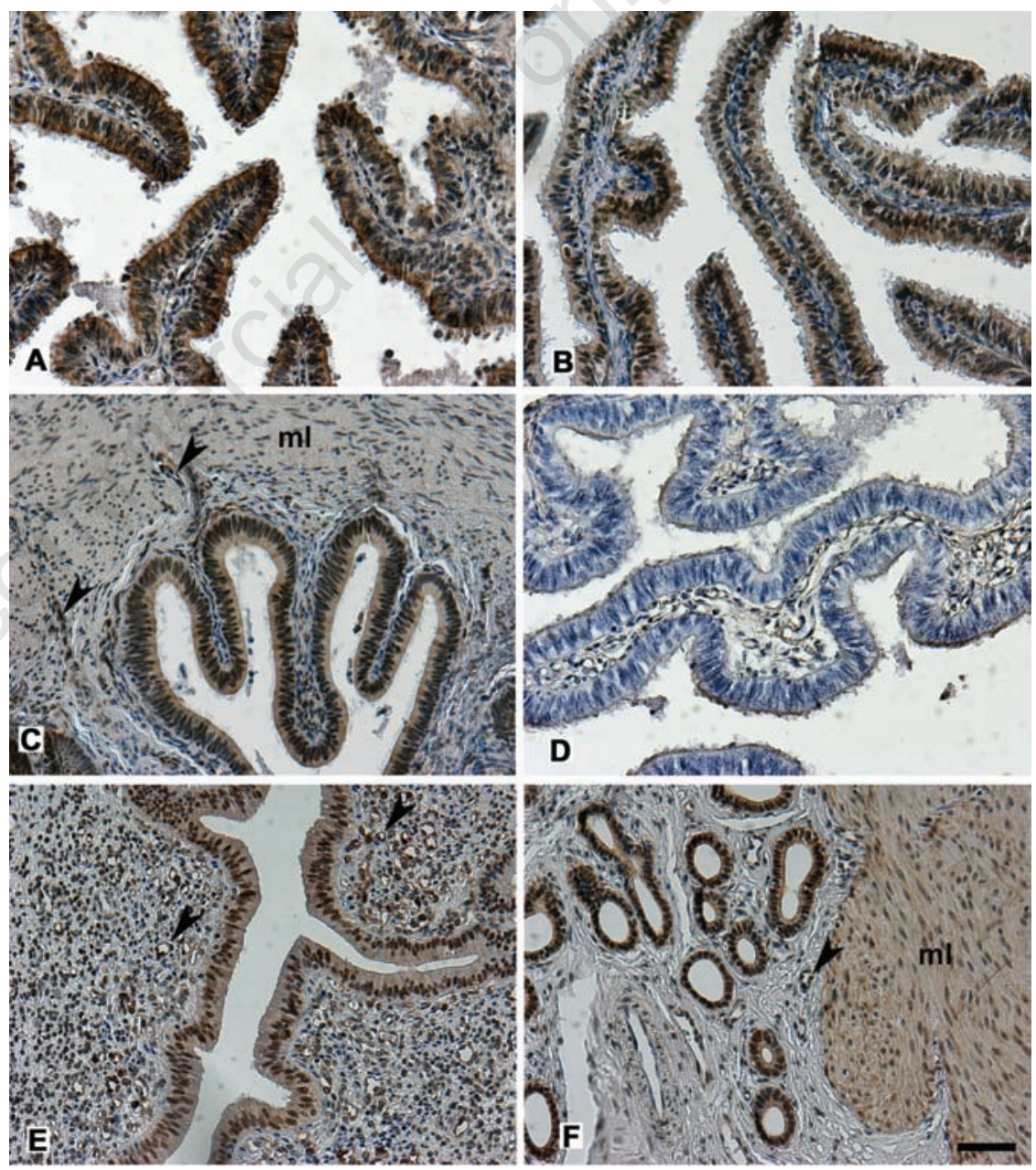

Figure 5. Immunohistochemical localization of PGRMC1 in bovine oviduct and uterus. PGRMC1 is expressed in the different tracts of the oviduct, infundibulum (A), ampulla (B) and isthmus (C) in luminal epithelium, in the muscle layers ( $\mathrm{ml}$ ) and in the vessels (arrowheads). In the uterus PGRMC1 is localized in luminal $(E)$ and glandular $(F)$ epithelium, in the muscle layers $(\mathrm{ml})$ and in the endothelial cells (arrowheads). Note that the nuclear staining of epithelial cells is intense both in oviduct and uterus. No immunoreactivity was seen in negative control where incubation with the primary antibody had been omitted(D). Final magnification, 200X; scale bar, $50 \mu \mathrm{m}$. 
mouse placenta and associated membranes with the most abundant expression in smooth muscle of the placental vasculature, villous capillaries and the syncytiotrophoblast suggesting that this protein functions in events important to early pregnancy, including cellular differentiation, modulation of apoptosis and steroidogenesis. ${ }^{10}$ Therefore, the study of PGRMC1 localization and expression during pregnancy in the cow would be of particular interest since dissimilarities between species could be due to the different involvement of the endometrium in the process of placentation in these species. Rodents and primates are characterized by an haemochorial placenta while cows have a synepitheliochorial placenta. Further studies are needed in order to confirm this hypothesis.

In conclusion, the present immunohistochemical study showed that PGRMC1 is located in various compartments of the bovine female reproductive organs. Despite some difference in PGRMC1 expression have been reported in human and mouse, our data suggest that with the exception of the corpora lutea, PGRMC1 localization does not seem to be differentially regulated during different stages of the estrous cycle. However, a quantitative study must be conducted in order to clarify the phase-independency of PGRMC1 expression in this species.

\section{References}

1. Cahill MA. Progesterone receptor membrane component 1: an integrative review. J Steroid Biochem Mol Biol 2007;105:16-36.

2. Nolte I, Jeckel D, Wieland FT, Sohn K. Localization and topology of ratp28, a member of a novel family of putative steroid-binding proteins. Biochim Biophys Acta 2000; 1543:123-30.

3. Sakamoto H, Ukena K, Takemori H, Okamoto M, Kawata M, Tsutsui K. Expression and localization of 25-Dx, a membrane-associated putative progesterone-binding protein, in the developing Purkinje cell. Neuroscience 2004;126:325-34.

4. Beausoleil SA, Jedrychowski M, Schwartz D, Elias JE, Villen J, Li J, et al. Large-scale characterization of HeLa cell nuclear phosphoproteins. Proc Natl Acad Sci USA 2004;101: 12130-5.

5. Sauer G, Korner R, Hanisch A, Ries A, Nigg EA, Sillje HH. Proteome analysis of the human mitotic spindle. Mol Cell Proteomics 2005;4:35-43.

6. Nousiainen M, Sillje HH, Sauer G, Nigg EA, Korner R. Phosphoproteome analysis of the human mitotic spindle. Proc Natl Acad Sci USA 2006;103:5391-6.

7. Lodde V, Peluso JJ. A novel role for proges- terone and progesterone receptor membrane component 1 in regulating spindle microtubule stability during rat and human ovarian cell mitosis. Biol Reprod 2011;84:715-22.

8. Lodde V, Peluso JJ, Franciosi F, Luciano AM. A novel role for progesteronereceptor membrane component-1 (PGRMC1) in regulating mitosis and meiosis. Proc. 34th National Congress of the Italian Society of Histochemistry, San Benedetto del Tronto, Italy, June 7-9, 2011. Eur J Histochem 2011; 55(s1):4.

9. Peluso JJ. Progesterone Signaling Mediated Through Progesterone Receptor Membrane Component-1 in Ovarian Cells with Special Emphasis on Ovarian Cancer. Steroids 2011; 76:903-9.

10. Zhang L, Kanda Y, Roberts DJ, Ecker JL, Losel R, Wehling M, et al. Expression of progesterone receptor membrane component 1 and its partner serpine $1 \mathrm{mRNA}$ binding protein in uterine and placental tissues of the mouse and human. Mol Cell Endocrinol 2008;287:819.

11. Chen J, Hannan N, Mak Y, Nicholls P, Zhang J, Rainczuk A, et al. Proteomic Characterization of Mid-Proliferative and Mid-Secretory Human Endometrium. J Proteome Res 2009; 8:2032-2044.

12. Peluso JJ, Pappalardo A, Losel R, Wehling M. Progesterone membrane receptor component 1 expression in the immature rat ovary and its role in mediating progesterone's antiapoptotic action. Endocrinology 2006;147: $3133-40$.

13. Engmann L, Losel R, Wehling M, Peluso JJ. Progesterone regulation of human granulosa/uteal cell viability by an RU486-independent mechanism. J Clin Endocrinol Metab 2006;91:4962-8.

14. McRae RS, Johnston HM, Mihm M, O'Shaughnessy PJ. Changes in mouse granulosa cell gene expression during early luteinization. Endocrinology 2005;146:30917.

15. Jiang H, Whitworth KM, Bivens NJ, Ries JE, Woods RJ, Forrester LJ, et al. Large-scale generation and analysis of expressed sequence tags from porcine ovary. Biol Reprod 2004; 71:1991-2002.

16. Kowalik MK, Kotwica J. Progesterone receptor membrane component 1 (PGRMC1) gene expression in corpus luteum during the estrous cycle in cows. Reprod Biol 2008;8: 291-7.

17. Peluso JJ, Liu X, Gawkowska A, Lodde V, Wu CA. Progesterone inhibits apoptosis in part by PGRMC1-regulated gene expression. Mol Cell Endocrinol 2010;320:153-61.

18. Peluso JJ, Romak J, Liu X. Progesterone receptor membrane component-1 (PGRMC1) is the mediator of progesterone's antiapoptotic action in spontaneously immortalized granulosa cells as revealed by PGRMC1 small interfering ribonucleic acid treatment and functional analysis of PGRMC1 mutations. Endocrinology 2008;149:534-43.

19. Luciano AM, Lodde V, Franciosi F, Ceciliani F, Peluso JJ. Progesterone receptor membrane component 1 expression and putative function in bovine oocyte maturation, fertilization, and early embryonic development. Reproduction 2010;140:663-72.

20. Wood JR, Dumesic DA, Abbott DH, Strauss JF, 3rd. Molecular abnormalities in oocytes from women with polycystic ovary syndrome revealed by microarray analysis. J Clin Endocrinol Metab 2007;92:705-13.

21. Aparicio IM, Garcia-Herreros M, O'Shea LC, Hensey C, Lonergan P, Fair T. Expression, regulation, and function of progesterone receptors in bovine cumulus oocyte complexes during in vitro maturation. Biol Reprod 2011;84:910-21.

22. Ireland JJ, Murphee RL, Coulson PB. Accuracy of predicting stages of bovine estrous cycle by gross appearance of the corpus luteum. J Dairy Sci 1980;63:155-60.

23. Fields MJ, Fields PA. Morphological characteristics of the bovine corpus luteum during the estrous cycle and pregnancy. Theriogenology 1996;45:1295-325.

24. Miyamoto Y, Skarzynski DJ, Okuda K. Is tumor necrosis factor alpha a trigger for the initiation of endometrial prostaglandin $\mathrm{F}$ (2alpha) release at luteolysis in cattle? Biol Reprod 2000;62:1109-15.

25. Bauersachs S, Ulbrich SE, Gross K, Schmidt SE, Meyer HH, Einspanier R, et al. Gene expression profiling of bovine endometrium during the oestrous cycle: detection of molecular pathways involved in functional changes. J Mol Endocrinol 2005;34:889-908.

26. Nilsson EE, Skinner MK. Progesterone regulation of primordial follicle assembly in bovine fetal ovaries. Mol Cell Endocrinol 2009;313:9-16.

27. Nilsson EE, Stanfield J, Skinner MK. Interactions between progesterone and tumor necrosis factor-alpha in the regulation of primordial follicle assembly. Reproduction 2006;132:877-86.

28. Rae MT, Menzies GS, Bramley TA. Bovine ovarian non-genomic progesterone binding sites: presence in follicular and luteal cell membranes. J Endocrinol 1998;159:413-27.

29. Ace CI, Okulicz WC. Microarray profiling of progesterone-regulated endometrial genes during the rhesus monkey secretory phase. Reprod Biol Endocrinol 2004;2:54.

30. Wu W, Shi SQ, Huang HJ, Balducci J, Garfield RE. Changes in PGRMC1, a potential progesterone receptor, in human myometrium during pregnancy and labour at term and preterm. Mol Hum Reprod 2011;17:233-42. 